\title{
Nuclear morphometric features in benign breast tissue and risk of subsequent breast cancer
}

\author{
Yan Cui · Esther A. Koop · Paul J. van Diest · \\ Rita A. Kandel · Thomas E. Rohan
}

Received: 25 July 2006/ Accepted: 1 September 2006/Published online: 24 October 2006

(C) Springer Science+Business Media B.V. 2006

\begin{abstract}
Certain nuclear morphometric features measured in breast tumor tissue have been shown to predict the prognosis of breast cancer patients. However, the application of these features to predicting risk of breast cancer development has received little attention. We conducted a case-control study to evaluate nuclear morphometric features in benign breast tissue in association with subsequent breast cancer risk. The study was nested within a cohort of 4,888 women with a histopathologic diagnosis of benign breast disease (BBD) and involved 61 cases and 71 controls, amongst whom there were 53 matched case-control sets. Conditional logistic regression models were fitted to assess various measurements of nuclear size and nuclear shape factors in relation to subsequent breast cancer risk. In multivariate analysis, subsequent breast cancer risk was positively associated with a nuclear shape factor that takes the shortest nuclear axis and the longest nuclear
\end{abstract}

\section{Y. Cui $(\bowtie)$}

Department of Epidemiology and Population Health, Albert Einstein College of Medicine, 1300 Morris Park Ave, Belfer 1301D, Bronx, NY 10461, USA

e-mail: ycui@aecom.yu.edu

E. A. Koop · P. J. van Diest

Department of Pathology, University Medical Center

Utrecht, Utrecht, The Netherlands

R. A. Kandel

Department of Pathology and Laboratory Medicine, Mt. Sinai Hospital, University of Toronto, Toronto, Canada

\section{T. E. Rohan}

Department of Epidemiology and Population Health, Albert Einstein College of Medicine, 1300 Morris Park Ave, Belfer 1301B, Bronx, NY 10461, USA axis into consideration simultaneously (highest quartile versus lowest 3 quartiles: odds ratio $=3.07,95 \%$ confidence limits $=1.61,5.84)$. In contrast, there was no alteration in subsequent breast cancer risk in association with nuclear size features and other shape factors. In conclusion, our study results suggest that the shape factor that takes both the shortest nuclear axis and the longest nuclear axis into consideration might be of value to predict subsequent development of breast cancer among women with BBD.

Keywords Benign breast disease - Breast cancer . Morphometry $\cdot$ Nuclear size $\cdot$ Nuclear shape

\section{Introduction}

Benign breast disease (BBD), in addition to certain hormonal, anthropometric, and lifestyle factors, is a well-established risk factor for breast cancer [1, 2]. However, BBD comprises a broad spectrum of histological entities [3]. Both epidemiologic and experimental studies suggest that non-atypical and atypical proliferative changes represent successive steps preceding the development of in situ cancer and then invasive carcinoma of the breast [4]. However, only a small fraction of women will eventually develop breast cancer after their diagnosis of BBD [5]. Therefore, it is important to differentiate BBD patients with a high risk of subsequent development of breast cancer from those with a low risk. Our understanding regarding this issue, however, is rather limited, although previous studies have suggested that factors such as type of histological subtype (e.g., atypical hyperplasia), menopausal status, and family history of breast cancer, 
might modify breast cancer risk among women with BBD [6].

Computerized image analysis and morphometry can quantify a number of nuclear morphometric features such as nuclear size, nuclear shape, and chromatin texture [7]. The evaluation of these features may facilitate the diagnosis and management of breast cancer patients [8-10]. Indeed, certain nuclear morphometric features measured in breast tumor tissue have been shown to predict the prognosis of breast cancer patients [11-15]. Furthermore, a study by Mommers et al. [16] observed that normal breast tissue or usual ductal hyperplasia harbored nuclear morphometric changes that might be used to predict subsequent development of breast cancer. In the study reported here, we conducted a nested case-control study to evaluate whether nuclear morphometric features as evaluated in tissue sections of BBD may be related to the risk of subsequent breast cancer among patients with BBD.

\section{Methods}

\section{Study population}

The present investigation was undertaken using histological sections from a previous case-control study nested within the cohort of 4,888 women in the Canadian National Breast Screening Study (NBSS) who were diagnosed histopathologically with BBD during the active follow-up phase of the NBSS [17]. The NBSS is a multi-center randomized, controlled trial of screening for breast cancer among 89,835 women aged 40-59 years at recruitment. The design of the NBSS and population characteristics have been described in detail elsewhere [18, 19]. Recruitment took place between 1980 and 1985, and study subjects were followed actively until 1988. Eligibility for the study was restricted to women with no history of breast cancer (in situ or invasive). The NBSS was approved by the appropriate Institutional Review Boards, and the study described here involved the analysis of material and data from that study in accordance with the approved study design. Informed consent was obtained from all study participants.

\section{Diagnosis of BBD}

In the NBSS, women who had clinical or radiologic evidence of breast lesion underwent either a needle aspiration or a biopsy. Diagnosis of BBD was performed by a reference pathologist. Our study was restricted to women who had no evidence of either in situ or invasive breast cancer on their initial surgical biopsy. Women with a history of BBD were not excluded from the analyses. During the follow-up period, we identified 4,888 women with a histopathologic diagnosis of BBD, who were followed up for the subsequent development of breast cancer.

\section{Selection of cases and controls}

Incident cases of breast cancer were ascertained by record linkage with the provincial cancer registries, and death clearance was performed by linkage to the Canadian National Mortality Database [18, 19]. The dates of the linkages varied by province, ranging from late 1988 to early 1991. A total of 16 subjects with ductal carcinoma in situ and 76 subjects with invasive carcinoma were ascertained among the cohort of women with BBD. Potential control subjects were women with BBD who had not developed breast cancer (but were alive at) by the date of diagnosis of the corresponding case subject. Five controls were selected randomly (with replacement) for each case from those non-cases available within strata defined by screening center, NBSS study arm, year of birth (if possible to the nearest year, and mostly within 2 years), and age at diagnosis of BBD. For the study reported here, 61 case subjects and 71 control subjects (including 53 matched case-control sets) were included.

\section{Questionnaire}

Upon enrollment in the NBSS, all participants completed a questionnaire that sought information on demographic characteristics and risk factors for breast cancer, including menstrual and reproductive histories and family history of breast cancer.

\section{Morphometry}

Morphometric measurements were performed on H\&E stained slides, using the QPRODIT interactive videooverlay system (Leica, Cambridge, UK). About 50 nuclei were selected in the most representative areas of the slide (selected by a breast pathologist), and their contours were traced manually using a $100 \times$ objective (final magnification about 3,000×) [20]. Mean and standard deviation of nuclear area, perimeter, diameter, shortest axis, longest axis, and axis ratio were calculated, as well as different shape factors. The shape factors were calculated by the following formulas: Form_AR $=(1 /$ 4) $*$ pi $*$ longest axis $*$ shortest axis; Form_PE = $4 *$ pi $*$ area/(perimeter squared); $\quad$ Form_NCI $=$ 
perimeter/sqrt (area); Contour ratio $=$ perimeter squared $/ 4 *$ pi $*$ area; and Roundness = perimeter/ $(2 *$ sqrt $($ pi $*$ area $))$. All morphometric assessments were performed by one observer without knowledge of patient outcome.

\section{Statistical analysis}

Morphometric measurements were first compared between cases and controls using Student's $t$-test. Subsequently, the measurements were categorized by quartiles and then odds ratios (OR) and 95\% confidence limits (CLs) were calculated for the risk of breast cancer for those in the highest quartile level compared to that for those in the lowest 3 quartile levels using conditional logistic regression. In multivariate analyses, we controlled for age at menarche $(<13,13,14+)$, age at first live birth (nulliparous, $<23$, 23-26, 27+), menopausal status (pre-, peri-, post-), oral contraceptive use (ever versus never), postmenopausal estrogen use (ever vs. never), body mass index $(<25$, $25+$ ), family history of breast cancer, and the presence of hyperplasia in the benign tissue. All statistical analyses were performed in SAS 9.1 (SAS Institute, Cary, NC). $P$-values were two-sided.

\section{Results}

Table 1 summarizes the distribution of selected characteristics among the cases and controls. Overall, few differences between the cases and controls were observed for age at menarche, age at first live birth, menopausal status, oral contraceptive use, postmenopausal estrogen use, body mass index, family history of breast cancer, and the presence of hyperplasia in benign tissue.

There was little difference between the cases and controls with respect to nuclear morphometric features including mean area, standard deviation (SD) of area, perimeter, diameter, shortest axis, and longest axis, as well as such shape factors as Form_PE, Form_NCI, contour, and roundness (Table 2). In contrast, the shape factor Form_AR was greater among cases than among controls. Furthermore, subjects with hyperplasia had greater measures of some nuclear size features including mean area, SD of area, perimeter, diameter, and longest axis, and the shape factor Form_AR than did subjects without hyperplasia (data not shown).

Quartile analyses revealed that subsequent breast cancer risk was increased in association with the shape factor Form_AR, but not with the other nuclear morphometric measurements (Table 3). Compared to
Table 1 Distribution of selected characteristics among breast cancer cases and non-cases

\begin{tabular}{|c|c|c|c|}
\hline & \multicolumn{2}{|l|}{$N(\%)$} & \multirow[t]{2}{*}{$P$-value } \\
\hline & Cases & Controls & \\
\hline \multicolumn{4}{|c|}{ Age at menarche } \\
\hline$<13$ & $30(49)$ & $26(37)$ & 0.29 \\
\hline 13 & $13(21)$ & $22(31)$ & \\
\hline $14+$ & $18(30)$ & $23(32)$ & \\
\hline \multicolumn{4}{|c|}{ Age at first live birth } \\
\hline Nulliparous & $11(18)$ & $9(13)$ & 0.84 \\
\hline$<23$ & $22(36)$ & $29(41)$ & \\
\hline $23-26$ & $19(31)$ & $23(32)$ & \\
\hline $27+$ & $9(15)$ & $10(14)$ & \\
\hline \multicolumn{4}{|c|}{ Menopausal status } \\
\hline Pre- & $30(49)$ & $31(44)$ & 0.71 \\
\hline Peri- & $9(15)$ & $14(20)$ & \\
\hline Post- & $22(36)$ & $26(36)$ & \\
\hline \multicolumn{4}{|c|}{ Ever used oral contraceptives } \\
\hline Yes & $35(57)$ & $42(60)$ & 0.76 \\
\hline No & $26(43)$ & $28(40)$ & \\
\hline Missing & 0 & 1 & \\
\hline \multicolumn{4}{|c|}{ Ever used postmenopausal estrogens } \\
\hline Yes & $15(25)$ & $15(22)$ & 0.70 \\
\hline No & $46(75)$ & $54(78)$ & \\
\hline Missing & 0 & 2 & \\
\hline \multicolumn{4}{|c|}{ Body mass index $\left(\mathrm{kg} / \mathrm{m}^{2}\right)$} \\
\hline$<25^{\circ}$ & $32(53)$ & $41(58)$ & 0.42 \\
\hline $25-<30$ & $27(44)$ & $25(35)$ & \\
\hline $30+$ & $2(3)$ & $5(7)$ & \\
\hline \multicolumn{4}{|c|}{ Family history of breast cancer } \\
\hline Yes & $23(38)$ & $28(39)$ & 0.84 \\
\hline No & $38(62)$ & $43(61)$ & \\
\hline \multicolumn{4}{|c|}{ Hyperplasia in benign tissue } \\
\hline Absent & $34(59)$ & $47(68)$ & 0.27 \\
\hline Present & $24(41)$ & $22(32)$ & \\
\hline Missing & 3 & 2 & \\
\hline
\end{tabular}

BBD subjects with Form_AR equal to or less than 0.986, subjects with Form_AR greater than 0.986 had a more than three-fold increased risk of developing breast cancer subsequently $(\mathrm{OR}=3.07,95 \% \mathrm{CL}=$ $1.61,5.84)$. When the analyses were repeated using unconditional logistic regression, which enabled all the available cases and controls to be included, the results did not change substantially.

\section{Discussion}

We found that breast cancer risk in women with BBD was positively associated with the shape factor Form_AR, a measurement that takes the shortest nuclear axis and the longest nuclear axis into consideration simultaneously. In contrast, there was no alteration in risk in association with nuclear area, SD of nuclear area, nuclear perimeter, nuclear diameter, shortest nuclear axis, longest nuclear axis, and other shape 
Table 2 Comparison of nuclear morphometric features in benign breast tissue between breast cancer cases and non-cases

\begin{tabular}{|c|c|c|c|}
\hline \multirow{2}{*}{$\begin{array}{l}\text { Morphometric } \\
\text { measurements }\end{array}$} & \multicolumn{2}{|c|}{ Mean (standard deviation) } & \multirow{2}{*}{$\begin{array}{l}P- \\
\text { value }\end{array}$} \\
\hline & $\begin{array}{l}\text { Cases } \\
(n=61)\end{array}$ & $\begin{array}{l}\text { Controls } \\
(n=71)\end{array}$ & \\
\hline $\begin{array}{l}\text { Mean nuclear area } \\
\left(\mu \mathrm{m}^{2}\right)\end{array}$ & $26.8(7.5)$ & $25.3(7.2)$ & 0.25 \\
\hline $\begin{array}{l}\text { SD of nuclear } \\
\text { area }\left(\mu \mathrm{m}^{2}\right)\end{array}$ & $5.2(1.8)$ & $5.0(1.6)$ & 0.43 \\
\hline $\begin{array}{l}\text { Nuclear perimeter } \\
\quad(\mu \mathrm{m})\end{array}$ & $19.7(2.7)$ & $19.3(2.7)$ & 0.37 \\
\hline $\begin{array}{l}\text { Nuclear diameter } \\
\quad(\mu \mathrm{m})\end{array}$ & $5.8(0.8)$ & $5.6(0.8)$ & 0.23 \\
\hline $\begin{array}{l}\text { Shortest nuclear } \\
\text { axis }(\mu \mathrm{m})\end{array}$ & $4.8(0.7)$ & $4.6(0.7)$ & 0.16 \\
\hline $\begin{array}{l}\text { Longest nuclear } \\
\text { axis }(\mu \mathrm{m})\end{array}$ & $7.1(1.0)$ & $7.0(1.0)$ & 0.53 \\
\hline Axis ratio & $1.5(0.1)$ & $1.6(0.2)$ & 0.15 \\
\hline Form_AR & $0.984(0.005)$ & $0.981(0.007)$ & 0.0089 \\
\hline Form_PE & $0.844(0.037)$ & $0.831(0.045)$ & 0.083 \\
\hline Form_NCI & $3.874(0.095)$ & $3.909(0.122)$ & 0.071 \\
\hline Contour & $1.198(0.061)$ & $1.221(0.080)$ & 0.068 \\
\hline Roundness & $1.093(0.027)$ & $1.103(0.034)$ & 0.071 \\
\hline
\end{tabular}

factors. Although subjects with hyperplasia had greater measures of Form_AR than did subjects without hyperplasia, we adjusted for hyperplasia, suggesting that the association with Form_AR is independent of that due to the presence of hyperplasia.

Shape is one of the factors that pathologists use in assessing nuclear atypicality. Shape factors have been shown to have prognostic value in breast cancer [21-23], renal cell cancer [24], colorectal cancer [25], squamous cell carcinoma of the larynx [26], melanoma [27], and rhabdomyosarcoma [28]. Apparently, alterations in nuclear shape can already be present at the earliest stages of carcinogenesis. This has in the breast also been shown for nuclear chromatin patterns [29].

To date, only one study has been published that assessed morphometric features in association with subsequent development of breast cancer among women with BBD [16]. That study found positive associations for mean nuclear area, nuclear diameter, nuclear perimeter, and the longest nuclear axis, but no associations for SD of the nuclear area and the shortest nuclear axis; shape factors were not evaluated. However, potential confounding factors were not controlled for. In contrast to these findings, nuclear size features were not associated with risk in the present study, which may perhaps be explained by differences in tissue processing procedures.

Our case-control study was nested in a cohort of patients with histopathologically confirmed BBD and our findings are likely to be internally valid. Biased measurement of the study exposures was not likely a source of error, given that the morphometric features were assessed without knowledge of the patient outcome status. Our study power, however, was limited by the relatively small sample size, due to which we were not able to evaluate modifying effects by welldocumented risk factors of breast cancer. Moreover, residual confounding might still exist, although to minimize confounding we controlled for menstrual and reproductive history, exogenous estrogen use, body

Table 3 Risk of Subsequent development of breast cancer in association with nuclear morphometric features ${ }^{\mathrm{a}}$

\begin{tabular}{lllr}
\hline Morphometric measurements & Cut-off value & OR (95\% CL) & Model 2 \\
\cline { 2 - 4 } & & Model 1 & $0.94(0.50,1.78)$ \\
\hline Mean nuclear area $\left(\mu \mathrm{m}^{2}\right)$ & 31.2 & $1.28(0.73,2.25)$ & $1.11(0.59,2.07)$ \\
SD of nuclear area $\left(\mu \mathrm{m}^{2}\right)$ & 6.1 & $1.33(0.76,2.31)$ & $0.85(0.47,1.55)$ \\
Nuclear perimeter $(\mu \mathrm{m})$ & 21.4 & $1.14(0.70,1.93)$ & $0.95(0.50,1.79)$ \\
Nuclear diameter $(\mu \mathrm{m})$ & 6.3 & $1.29(0.73,2.27)$ & $1.18(0.62,2.26)$ \\
Shortest nuclear axis $(\mu \mathrm{m})$ & 5.2 & $1.62(0.92,2.86)$ & $0.95(0.50,1.81)$ \\
Longest nuclear axis $(\mu \mathrm{m})$ & 8.0 & $1.34(0.75,2.39)$ & $0.71(0.33,1.54)$ \\
Axis ratio & 1.6 & $0.59(0.30,1.17)$ & $3.07(1.61,5.84)$ \\
Form_AR & 0.986 & $2.45(1.42,4.22)$ & $1.57(0.83,2.97)$ \\
Form_PE & 0.867 & $1.22(0.71,2.08)$ & $1.18(0.61,2.27)$ \\
Form_NCI & 3.935 & $1.07(0.58,1.98)$ & $1.22(0.63,2.35)$ \\
Contour & 1.236 & $1.13(0.61,2.10)$ & $1.07(0.58,1.98)$ \\
Roundness & 1.110 & $0.61,2.27)$
\end{tabular}

${ }^{a}$ Analyses were conducted among 53 matched case-control sets by comparing the highest quartile versus the lowest 3 quartiles in conditional logistic regression models

${ }^{\mathrm{b}}$ Adjusted for matching variables

${ }^{\mathrm{c}}$ Adjusted for matching variables, age at menarche $(<13,13,14+)$, age at first live birth (nulliparous, $\left.<23,23-26,27+\right)$, menopausal status (pre-, peri-, post-), oral contraceptive use (ever vs. never), postmenopausal estrogen use (ever versus never), body mass index $(<25,25+)$, family history of breast cancer, and the presence of hyperplasia in the benign tissue 
mass index, and family history of breast cancer in multivariate analyses.

In conclusion, our study results suggest that the shape factor that takes both shortest nuclear axis and longest nuclear axis into consideration might be of value to predict subsequent development of breast cancer among patients with BBD. Given the limitations of our study, larger studies are warranted to confirm our study results.

Acknowledgments We are indebted to the study participants for their dedication and commitment.

\section{References}

1. Colditz GA (2005) Epidemiology and prevention of breast cancer. Cancer Epidemiol Biomarkers Prev 14(4): 768-772

2. Fitzgibbons PL, Henson DE, Hutter RV (1998) Benign breast changes and the risk for subsequent breast cancer: an update of the 1985 consensus statement. Cancer Committee of the College of American Pathologists. Arch Pathol Lab Med 122(12): 1053-1055

3. Rohan TE, Kandel RA (2002) Breast. In: Franco EL, Rohan TE (eds) Cancer precursors: epidemiology, detection, and prevention. Springer, New York

4. Lakhani SR (1999) The transition from hyperplasia to invasive carcinoma of the breast. J Pathol 187(3): 272-278

5. Elmore JG, Gigerenzer G (2005) Benign breast disease-the risks of communicating risk. N Engl J Med 353(3): 297-299

6. Schnitt SJ (2003) Benign breast disease and breast cancer risk: morphology and beyond. Am J Surg Pathol 27(6): 836-841

7. Gil J, Wu H, Wang BY (2002) Image analysis and morphometry in the diagnosis of breast cancer. Microsc Res Tech 59(2): 109-118

8. Boon ME, Trott PA, van Kaam H, Kurver PJ, Leach A, Baak JP (1982) Morphometry and cytodiagnosis of breast lesions. Virchows Arch A Pathol Anat Histol 396(1): 9-18

9. Ruiz A, Almenar S, Callaghan RC, Llombart-Bosch A (1999) Benign, preinvasive and invasive ductal breast lesions. A comparative study with quantitative techniques: morphometry, image- and flow cytometry. Pathol Res Pract 195(11): 741-746

10. Skjorten F, Kaaresen R, Jacobsen U, Skaane P, Amlie E (1991) Nuclear morphometry of benign and malignant breast lesions. Eur J Surg Oncol 17(4): 350-353

11. van der Linden HC, Baak JP, Lindeman J, Hermans J, Meyer CJ (1986) Morphometry and breast cancer. II. Characterisation of breast cancer cells with high malignant potential in patients with spread to lymph nodes: preliminary results. J Clin Pathol 39(6): 603-609

12. Wolberg WH, Street WN, Mangasarian OL (1999) Importance of nuclear morphology in breast cancer prognosis. Clin Cancer Res 5(11): 3542-3548

13. Wolberg WH, Street WN, Mangasarian OL (1997) Computer-derived nuclear features compared with axillary lymph node status for breast carcinoma prognosis. Cancer 81(3): 172-179

14. Hoque A, Lippman SM, Boiko IV, Atkinson EN, Sneige N, Sahin A, Weber DM, Risin S, Lagios MD, Schwarting R,
Colburn WJ, Dhingra K, Follen M, Kelloff GJ, Boone CW, Hittelman WN (2001) Quantitative nuclear morphometry by image analysis for prediction of recurrence of ductal carcinoma in situ of the breast. Cancer Epidemiol Biomarkers Prev 10(3): 249-259

15. Kronqvist P, Kuopio T, Collan Y (1998) Morphometric grading of invasive ductal breast cancer. I. Thresholds for nuclear grade. Br J Cancer 78(6): 800-805

16. Mommers EC, Page DL, Dupont WD, Schuyler P, Leonhart AM, Baak JP, Meijer CJ, van Diest PJ (2001) Prognostic value of morphometry in patients with normal breast tissue or usual ductal hyperplasia of the breast. Int J Cancer 95(5): 282-285

17. Rohan TE, Hartwick W, Miller AB, Kandel RA (1998) Immunohistochemical detection of c-erbB-2 and p53 in benign breast disease and breast cancer risk. J Natl Cancer Inst 90(17): 1262-1269

18. Miller AB, Baines CJ, To T, Wall C (1992) Canadian National Breast Screening Study: 1. Breast cancer detection and death rates among women aged 40 to 49 years. CMAJ 147(10): 1459-1476

19. Miller AB, Baines CJ, To T, Wall C (1992) Canadian National Breast Screening Study: 2. Breast cancer detection and death rates among women aged 50 to 59 years. CMAJ 147(10): 1477-1488

20. Fleege JC, van Diest PJ, Baak JP (1990) Computer assisted efficiency testing of different sampling methods for selective nuclear graphic tablet morphometry. Lab Invest 63(2): 270-275

21. Chiusa L, Margaria E, Pich A (2000) Nuclear morphometry in male breast carcinoma: association with cell proliferative activity, oncogene expression, DNA content and prognosis. Int J Cancer 89(6): 494-499

22. Giardina C, Renzulli G, Serio G, Caniglia DM, Lettini T, Ferri C, D'Eredita G, Ricco R, Delfino VP (1996) Nuclear morphometry in node-negative breast carcinoma. Anal Quant Cytol Histol 18(5): 374-382

23. Umbricht C, Oberholzer M, Gschwind R, Christen H, Torhorst J (1989) Prognostic significance (relapse, non-relapse) of nuclear shape parameters in lymph node negative breast cancer. Anal Cell Pathol 1(1): 11-23

24. Carducci MA, Piantadosi S, Pound CR, Epstein JI, Simons JW, Marshall FF, Partin AW (1999) Nuclear morphometry adds significant prognostic information to stage and grade for renal cell carcinoma. Urology 53(1): 44-49

25. Fernandez-Lopez F, Paredes-Cotore JP, Cadarso-Suarez C, Forteza-Vila J, Puente-Dominguez JL, Potel-Lesquereux J (1999) Prognostic value of nuclear morphometry in colorectal cancer. Dis Colon Rectum 42(3): 386-392

26. Dobros W, Gil K, Chlap Z, Olszewski E (1999) The use of nuclear morphometry for the prediction of survival in patients with advanced cancer of the larynx. Eur Arch Otorhinolaryngol 256(5): 257-261

27. Karbowniczek M, Chosia M, Domagala W (1999) Nuclear morphometry of MIB-1 positive and negative tumor cells in primary and metastatic malignant melanoma of the skin. Pol J Pathol 50(4): 235-241

28. Kazanowska B, Jelen M, Reich A, Tarnawski W, Chybicka A (2004) The role of nuclear morphometry in prediction of prognosis for rhabdomyosarcoma in children. Histopathology 45(4): 352-359

29. Mommers EC, Poulin N, Sangulin J, Meijer CJ, Baak JP, van Diest PJ (2001) Nuclear cytometric changes in breast carcinogenesis. J Pathol 193(1): 33-39 